\title{
Trabalho, Raça e Gênero na produção de fotografias: considerações a partir de uma experiência brasileira *
}

\author{
Trabajo, raza y género en la producción de fotografías: consideraciones desde una experiencia brasileña
} Work, race and gender in the production of photographs: Considerations from a Brazilian experience

\author{
Jaqueline Tittoni ${ }^{\text {a }}$ \\ Universidade Federal do Rio Grande do Sul, Brasil \\ jatittoni@gmail.com \\ ORCID: http://orcid.org/0000-0002-3450-080X \\ Diego Drescher De Castro \\ Universidade Federal do Rio Grande do Sul, Brasil \\ ORCID: http://orcid.org/0000-0002-7363-9476 \\ Arthur Gomes de Almeida \\ Universidade Federal do Rio Grande do Sul, Brasil \\ ORCID: http://orcid.org/0000-0002-7363-9476
}

DOI: https://doi.org/10.11144/Javeriana.cao32-58.trgpf Redalyc: http://www.redalyc.org/articulo.oa?id=20560207006

Recepção: 27/09/2018

Aprovação: 29/03/2019

\section{Resumo:}

Este artigo problematiza a relação entre produção de conhecimento, subjetividade e trabalho no contexto brasileiro. Para tal, aborda a relação entre colonialidade e descolonialidade no que tange ao campo epistemológico e suas imbricações nas relações de trabalho, tomando a subjetividade como eixo central destas análises. Do ponto de vista descolonial, evidencia os modos como se articulam os marcadores gênero e raça para mostrar os efeitos de colonização do trabalho fundamentado no modelo de homem branco ocidental. Para tanto, tomaremos estudo realizado com trabalhadoras da saúde, com a utilização de oficinas de produção de fotografia, para pensar os modos como estes marcadores aparecem nos cotidianos de trabalho.

Códigos JEL: I20, Z13

Palavras-chave: trabalho, conhecimento, subjetividade, fotografia.

\section{Resumen:}

Este artículo problematiza la relación entre producción de conocimiento, subjetividad y trabajo en el contexto brasileño. Para ello abordaremos la relación entre colonialidad y descolonialidad en lo que se refiere al campo epistemológico y sus imbricaciones en las relaciones de trabajo, tomando la subjetividad como eje central de estos análisis. Desde el punto de vista descolonial, evidencia los modos como se articulan los marcadores género y raza para mostrar los efectos de colonización del trabajo fundamentado en el modelo de hombre blanco occidental. Para ello, tomaremos un estudio realizado con trabajadoras de la salud, con la utilización de talleres de producción de fotografía, para pensar los modos como estos marcadores aparecen en los cotidianos de trabajo.

Códigos JEL: I20, Z13

Palabras clave: trabajo, subjetividad, conocimiento, fotografía.

\section{Abstract:}

This article problematizes the relationship between knowledge production, subjectivity and work in the brazilian context. Therefor, we will discuss the relationship between coloniality and decoloniality in what concerns the epistemological field and its imbrications in labor relations, where the subjectivity as the central axis of these analyzes. From a decolonial point of view, it shows the ways in which the markers of gender and race are articulated to show the colonization effects of the work based on the white man model. To do so, we will take a study done with health workers, using the methodologies of photography production workshops, to think about the ways these markers appear in everyday work.

JEL Codes: I20, Z13

Keywords: work, subjectivity, knowledge, photography.

\section{Autor notes:}

\footnotetext{
${ }^{\text {a }}$ Autora correspondente. Correio eletrônico: jatittoni@gmail.com
} 


\section{Introdução}

Este estudo discute inter-relações entre trabalho, conhecimento e subjetividade, buscando evidenciar algumas vozes e silêncios que aí se produzem, tendo como referência a perspectiva descolonial. Partindo do cenário brasileiro como ponto de referência, buscamos problematizar as relações entre produção de conhecimento e trabalho neste país, considerando os efeitos colonizadores do pensamento ocidental sobre o conhecimento, e do conhecimento sobre a subjetividade e o trabalho. Uma atitude crítica, portanto, com relação aos modos como a produção de conhecimento sobre o trabalho produz efeitos de poder sobre as configurações e os modos de trabalhar no Brasil.

Para tanto, tomamos a noção de crítica do pensamento foucaultiano articulada às artes de governar, ou seja, a crítica como "a arte de não ser governado de tal forma" (Foucault, 1990, p. 2). Para o autor, a atitude crítica é, ao mesmo tempo, parceira e adversária das artes de governar, forçando rupturas, recusas e deslocamentos. Esta perspectiva de crítica, como renúncia e mudança, coloca a noção de ética como elemento importante nas artes de governar, forçando a reflexão nas tensões entre as práticas de uma liberdade possível e suas condições de possibilidade e impossibilidades. A noção de ética no pensamento crítico foucaultiano, como nos aponta Orellana (2008), surge da crítica ao sujeito soberano, universal e fundador da episteme moderna, que traz como consequência a crítica ao sujeito moral. Esta posição aponta os deslocamentos e as rupturas que vão delineando singularidades e se atualizando no tempo e no espaço como experiência. Neste ponto, talvez possamos apostar que a crítica à colonialidade permanece viva no pensamento foucaultiano, apesar da força de colonialidade presente em sua obra, quando usado como conhecimento que perde sua potência de crítica e se afirmar verdade absoluta, conforme apontado por Spivak (2010). A autora segue sua crítica salientando que, ainda que em uma perspectiva crítica e pós-estrutural, Foucault afirma uma distinção entre o lugar do "intelectual" e dos demais saberes, tal qual Deleuze, que não aborda a complexidade da divisão internacional do trabalho ao tratar do movimento social "dos trabalhadores" como universal e homogêneo (Spivak, 2010).

Ao tomarmos a crítica como "um instrumento ou um meio para um devir" (Foucault, 1990, p. 3), pensamos nos efeitos de colonização que se impõe sobre o trabalho e o conhecimento no Brasil. A colonização se configura, em seu amplo aspecto, em estratégias de governo que se atualizam no curso da história e que mantém certas regularidades na manutenção da ordem colonizadora. Este tema, de grande complexidade num mundo digitalizado e de fronteiras expansivas, produz efeitos de subjetivação muito relevantes na medida em que a colonização das subjetividades produz-se tanto quanto a colonização dos territórios.

Assim, qualquer produção, seja ela acadêmica ou não, que pretenda falar a partir de uma perspectiva antihegemônica precisa levar em conta os processos de colonização, uma vez que a violência como forma de colonialidade ainda segue ditando os modos de pensar, trabalhar e viver. Por isto a importância de ressaltarmos a distinção entre colonialismo e colonialidade. Segundo Restrepo e Rojas (2010), enquanto o processo de colonialismo diz respeito ao aparato político-militar desenvolvido para garantir a exploração do trabalho e da riqueza da colônia em prol do colonizador, a colonialidade se define por ser um fenômeno histórico mais complexo, que se estende até o nosso presente. Segundo o autor, a colonialidade está vinculada aos jogos de poder que operam através da "naturalização de hierarquias territoriais, raciais, culturais e epistêmicas, possibilitando a reprodução de relações de dominação” (Restrepo \& Rojas, 2010, p. 15, tradução nossa).

Os processos coloniais incidem diretamente nas relações de trabalho e na produção de conhecimento na América Latina e os estudos descoloniais, ao assumirem uma posição crítica, podem colocar em análise a lógica disciplinar, sustentada na noção de homem branco sobre o conhecimento, o trabalho e as subjetividades. Criar um padrão específico de domínio sobre a heterogeneidade multi-étnica, cultural e linguística é estratégia do império e é constitutiva das práticas de domínio colonial. Deste modo, a tensão entre heterogeneidade e domínio atua como parte fundamental na formação do império e constitui as práticas de domínio coloniais (Cohen, 2004). 
A discussão aqui proposta problematiza o saber e o trabalho a partir de uma perspectiva que não busca a delimitação dos conceitos e sua localização histórica, mas como eles operam em contextos específicos. Nesse sentido, buscamos fundamentação na obra de Michel Foucault e em sua discussão acerca da perspectiva genealógica que

consiste na desconstrução ou desnaturalização das formas cristalizadas e instituídas, apontando para o caráter contingente que marca a constituição das mesmas, mostrando-as como frutos de uma historicidade e de determinadas condições de possibilidade. (Zambenedetti \& Silva, 2011, p. 455)

Assim, entender como saber e trabalho se articulam a partir da modernidade é fundamental para compreender os processos de colonização na América Latina e como estes incidem diretamente sobre a produção de subjetividade. Partindo desses pressupostos acerca da colonialidade do saber, do trabalho e, consequentemente, da subjetividade, problematizamos suas inter-relações a partir do estudo "O trabalho como arte - reinventando modos de viver e trabalhar", realizado na cidade de Porto Alegre - Brasil. Esta pesquisa, ancorada no pensamento foucaultiano, foi realizada com trabalhadoras e trabalhadores das políticas públicas de assistência e saúde, discutindo os modos de trabalhar e os cotidianos de trabalho, a partir da produção de imagens fotográficas e do acompanhamento das rotinas de trabalho destas profissionais. Ao partir de uma perspectiva crítica do próprio trabalho, pode-se abordar alguns aspectos da complexidade das tramas que se produzem nestas inter-relações.

A intervenção fotográfica enquanto estratégia metodológica objetiva tensionar as linhas de visibilidade, que indicam sobre os modos institucionalizados de trabalhar, com a produção de imagens (Tittoni, 2009). As fotografias produzidas, ao retratar o cotidiano de trabalho, abrem espaço para a problematização dos processos de colonialidade entremeados no fazer da saúde, da assistência e, também, do pesquisar. Nesta exposição, faremos um recorte deste estudo, trazendo para a análise duas imagens que mostram, com maior evidência, as questões de raça que atravessam o trabalho, definindo lugares e posições das trabalhadoras nas hierarquias de trabalho e nos modos de trabalhar.

\section{Descolonialidade, saber na modernidade}

Quando falamos na relação entre saber (produção de conhecimento) e trabalho desde uma perspectiva descolonial, partimos do pressuposto de que as linhas de força que transversalizam tais temáticas podem ser encaradas enquanto processo de produção de subjetividade. Ao abordar tal conceito, desde o pensamento foucaultiano, a subjetividade é deslocada do sentido de substância/essência e abordada como um constante processo de produção. Para o autor, a subjetividade pode ser definida como "a maneira pela qual o sujeito faz a experiência de si mesmo em um jogo de verdade" (Foucault, 2004, p. 236). Assim, tratam-se de processos de subjetivação que implicam as condições existentes para a experiência, ou seja, são as configurações socioeconômicas, históricas e culturais que criam certas redes onde a experiência pode/deve se realizar.

Em seu texto "O sujeito e o poder", Foucault (1995) discute que, ao estudar o poder, está ocupando-se do sujeito e dos modos como este se configura como efeito de poder. Para tanto, sugere três planos de abordagem do sujeito: os modos como este se coloca como objeto de conhecimento; os modos como se produz nas práticas divisórias, que divide os sujeitos em seu interior, e, também, entre si como ricos/pobres, normais/ anormais, saudáveis/doentes; e, por fim, os modos como o sujeito aprende a reconhecer-se a si mesmo ou, em outras palavras, se converte em sujeito através de práticas que o ligam à sua própria identidade.

A experiência de si produz-se como efeito de jogos de poder nas trajetórias pressionadas por marcadores sociais no contexto colonial -como classe, gênero e raça-, tal qual proposta nesta reflexão. A análise dos marcadores sociais e seus impactos nas relações de poder não foram discutidos por Foucault. Cabe lembrar que o autor concebe o poder como relaçóes e jogos de verdade, em que o poder e a rebeldia da liberdade não podem ser separados. Para ele: 
En el corazón mismo de la relación de poder, y "provocándola" de manera constante, se encuentran la obstinación de la voluntad y la intransitividad de la libertad. Más que hablar de un "antagonismo" esencial, sería preferible hablar de un "agonismo" - de una relación que es al mismo tiempo de incitación recíproca y de lucha. (Foucault, 1988, p. 17)

A liberdade aqui referida não está ligada a uma visão essencialista de sujeito e ao seu livre arbítrio, muito caras a uma perspectiva neoliberal, mas a uma posição ética, que, agonisticamente, torna visível as inquietações e mobiliza a resistência, a luta, a ruptura e a crítica.

Desde esta perspectiva, subjetividade e trabalho formam um campo de múltiplas tensões, marcados por relações de poder e de verdade que convergem para a produção de diferentes modos de ser do sujeito que trabalha. Este processo implica em elementos macro-políticos que remetem à configuração das relações Capital-Trabalho no capitalismo contemporâneo e às micropolíticas das práticas cotidianas, dos modos de viver e das experiências de si. Sujeito, verdade e poder demonstram, de certa forma, os temas aqui desenvolvidos: subjetividade, conhecimento e trabalho.

O arcabouço teórico que ampara tais temáticas ganha os contornos contemporâneos desde a modernidade, período compreendido a partir da transição do século XVIII para o século XIX, no qual, segundo Foucault (2000), é inaugurada a maneira moderna de pensar. Dreyfus e Rabinow (1995, p. 30), ao analisar a obra de Foucault, salientam que o autor não identifica o "surgimento" da episteme moderna, apontando um homem que não se reconhece mais em um mundo pautado por uma organização divina ou ao lado dos animais no quadro da história natural. Foucault nos apresenta o homem enquanto "duplo empírico-transcendental", remetendo ao lugar que este ocupa na episteme contemporânea. Essa figura ambígua que é, ao mesmo tempo, empírica e transcendental, representa a passagem de um ser que deixa de atuar apenas como observador e classificador, situado num plano externo, para um ser que se coloca tanto como sujeito, quanto como objeto dessa discursividade moderna. Tal concepção, como veremos mais adiante, vai ser fundamental para o entendimento desse "homem moderno" enquanto universal, a partir de um viés eurocêntrico.

Esse período de "passagem" da Episteme Clássica para a Episteme Moderna, compreendido na virada do século XVIII para o século XIX em uma Europa que ainda respira o Iluminismo, vai ser fundamental para a organização dos saberes tal qual a conhecemos na contemporaneidade. O século XVIII, chamado por Foucault de "século do disciplinamento dos saberes", define a organização destes como disciplina, criando e classificando novos saberes a partir de uma exclusão daquilo que se considerava como "falsos saberes" ou "não saberes". Tal movimento permitiu um reordenamento e normatização desses modos de conhecer, lançando as bases daquilo que viria a ser consideradas como "a ciência" em oposição às "ciências naturais", características da episteme clássica.

Nesse contexto, as universidades assumem a materialidade da produção de conhecimento da modernidade e se estabelecem, a partir de um lugar estratégico, como "grande aparelho uniforme dos saberes" (Foucault, 2005), com a função de fiscalizar, hierarquizar e validar o conhecimento produzido. Dessa forma, todo o saber que é considerado inadequado pela universidade acaba, se não totalmente excluído, pelo menos desconsiderado a priori. Assim, essa reconfiguração das universidades no contexto da episteme moderna produziu um disciplinamento dos saberes que ensejou o aparecimento de uma "regra nova que já não é a regra da verdade, mas a regra da ciência" (Foucault, 2005, p. 222).

Pode-se dizer que é nesse contexto das universidades, a partir da maneira moderna de pensar, que inaugurase a ciência, uma vez que "a ciência não existia antes do século XVIII" (Foucault, 2005, pp. 217-218). Essa ciência, considerada por muitos como linear e inabalável, detentora de verdades únicas, segue sustentandose a partir de um processo de negação e desvalorização de saberes que não são considerados científicos, encontrando, dentro das universidades, o principal campo de disputa entre diferentes verdades. Tais disputas funcionam a partir de uma lógica de exclusão e não pressupõem uma composição entre saberes, mas a imposição de uns em detrimento de outros.

Ainda que bastante complexa, a leitura foucaultiana do surgimento da episteme moderna encontra pelo menos uma grande lacuna. Ao dialogar com Kant e contextualizar o surgimento da maneira moderna e 
global de pensar a partir do Renascimento europeu, Foucault acaba por localizar e reforçar os modos de saber eurocêntricos. Walter Mignolo analisa tal questão:

\begin{abstract}
Las luces con las que Kant clamaba por la libertad y la madurez, y todavía más iluminación cuando Michel Foucault retomó la célebre pieza de Kant, desdibujaron el sentido presupuesto en el concepto kantiano de hombre y humanidad: el hecho de que el concepto Kantiano de hombre y humanidad tenía como referente la humanidad definida por el renacimiento Europeo y retomada por los filósofos de la ilustración. Sobre estos límites etnocéntricos se basó el concepto europeo de hombre, el cual sirvió para clasificar y descartar las personas "menos humanas" que poblaban el mundo más allá del corazón de Europa. (Mignolo, 2009, p. 25)
\end{abstract}

O predomínio da produção de conhecimento eurocêntrica e a universalização da figura do homem europeu como padrão influencia diretamente na produção de conhecimento no dito "terceiro mundo". Esse contexto acaba sendo importante, porque as universidades assumem um papel fundamental na colonização epistemológica latino-americana, principalmente a partir do final do século XVIII e início de século XIX, quando aumentam drasticamente em número no chamado "novo mundo". Cabe salientar que no contexto latino-americano, as universidades funcionam como enclaves da Europa, estabelecidos no continente americano, mas respondendo epistemologicamente aos padróes europeus. Tal estratégia diz respeito a uma visão eurocêntrica e colonialista de mundo, afinal, "como sabemos: o primeiro mundo tem conhecimento, o terceiro mundo tem cultura" (Mignolo, 2009).

Segundo Castro-Gómez (2007), as universidades latino-americanas estão submetidas a uma visão colonizada do mundo, ancorada em um modelo epistemológico implementado pela modernidade ocidental. $\mathrm{O}$ autor sustenta que a universidade contemporânea está inserida em uma "estrutura triangular da colonialidade", do ser, do poder e do saber. Ainda segundo o autor, a hierarquização arbórea e disciplinar do conhecimento e o lugar de fiscalização do saber ocupado pelas universidades reproduzem um modelo epistêmico moderno/colonial que ditaria o "ponto zero" do saber, o lugar quimérico do sujeito neutro que observa à distância seu objeto de estudo.

Nesse sentido, a proposta de um "Giro Decolonial" (Castro-Gómez, 2006) surge como processo de resistência aos modos de colonização do saber na contemporaneidade a partir de uma perspectiva descolonial. Segundo Costa (2014), a abordagem descolonial está ligada à história da América Latina: desde o início do século XVI até o presente. Tal perspectiva "enfatiza a continuidade das relações coloniais de poder (colonialidade do poder) através das categorias de gênero, raça e classe" e busca um "desligamento de epistemologias eurocêntricas", principalmente a partir da validação e afirmação de diferentes saberes e paradigmas. A partir dessa transgressão epistemológica, o objetivo que as Ciências Descoloniais inauguram é o de transformar o sujeito racializado, até então visto essencialmente como objeto de estudo, em sujeito de conhecimento, ou seja, transformar alguém que vinha sendo pensado a partir da visão de um terceiro, o colonizador, em sujeito de si e produtor de conhecimento sobre si e sobre seu mundo.

No Brasil, podemos pensar na criação da Lei 10.639/03, que regulamenta a obrigatoriedade do ensino da História da África e da cultura afro-brasileira nas escolas públicas e particulares, assim como nas universidades, e que vai ao encontro deste movimento descolonizador da produção e transmissão do conhecimento. Nesse sentido, devemos ter em mente que

descolonizar os currículos é mais um desafio para a educação escolar [e universitária]. Muito já denunciamos sobre a rigidez das grades curriculares, o empobrecimento do caráter conteudista dos currículos, a necessidade de diálogo entre escola, currículo e realidade social, a necessidade de formar professores e professoras reflexivos e sobre as culturas silenciadas nos currículos. (Gomes, 2012, p. 102)

É perceptível a importância da lei 10.639/03 neste processo de descolonização dos currículos, que é intrínseco ao desafio de pensarmos em um trabalho descolonizado. Assim como a inauguração dos Estudos Descoloniais, esta legislação, como as outras que normatizam o ensino das culturas historicamente marginalizadas, foi pensada a partir da luta dos movimentos sociais negros. Atualmente, transborda este 
nicho e encontra espaço -ainda que limitado- entre alguns alunos, alunas, professoras e professores, que começam a interessar-se pela temática, assim como reconhecer a sua importância. Gera-se, a partir disso, uma movimentação na estrutura curricular em direção à superação da colonialidade em nossa educação, promovendo reflexos no trabalho em sala de aula. A lei possibilitou a

construção de uma ruptura epistemológica e cultural causada pela introdução mais sistemática da discussão sobre a questão racial e a História da África na escola. Uma ruptura cuja ampliação tem se dado, com limites e avanços, por força da lei. E uma lei que não é somente mais uma norma: é resultado de ação política e da luta de um povo cuja história, sujeitos e protagonistas ainda são pouco conhecidos. (Gomes, 2012, pp. 103-104)

Compreender os modos pelos quais a cultura hegemônica, branca e elitista, silencia e marginaliza o ensino da cultura negra, das questões de gênero e dos movimentos sociais é algo que vem sendo feito também a partir desta lei. Este movimento descolonial da educação se potencializa cada vez mais no Brasil e em outros países da América Latina. Ainda assim, deve-se atentar para questões mais sutis que permeiam o ensino escolar básico, médio e, principalmente, superior no Brasil, e que advém dos silenciamentos e discriminações veladas que são características do racismo brasileiro. Racismo que se esconde por trás do mito da democracia racial, já que,

Nesse contexto, a discriminação racial se faz presente como fator de seletividade na instituição escolar e o silêncio é um dos rituais pedagógicos por meio do qual ela se expressa. Não se pode confundir esse silêncio com o desconhecimento sobre o assunto ou a sua invisibilidade. É preciso colocá-lo no contexto do racismo ambíguo brasileiro e do mito da democracia racial e sua expressão na realidade social e escolar. O silêncio diz de algo que se sabe, mas não se quer falar ou é impedido de falar. (Gomes, 2012, pp. 104-105)

Portanto, compreender este processo de silenciamento, assim como combatê-lo nos espaços de educação formal, é condição para uma prática descolonizadora da transmissão e produção de conhecimento. Assim, podemos pensar que a transformação estrutural advinda dessa legislação pode possibilitar a construção de uma educação anti-racista e descolonizadora, que produz uma ruptura epistemológica nos currículos e na formação dos professores, na medida em que este "falar" sobre a questão afro-brasileira e africana se torna público e legítimo.

Também no âmbito do trabalho, a invisibilidade e o silenciamento dos marcadores de raça se fazem presentes. A noção de racismo institucional definido, inicialmente, pelos ativistas integrantes do grupo Panteras Negras, como "a falha coletiva de uma organização em prover um serviço apropriado e profissional às pessoas por causa de sua cor, cultura ou origem étnica" (Carmichael \& Hamilton, 1967, p. 4), amplia o foco de análise dos marcadores de raça. Esta noção apresenta uma forma de racismo e reprodução da colonialidade que se amplia do âmbito privado e aborda uma percepção institucional, que pode operar nas organizações de diferentes formas. As análises críticas do trabalho, na mesma medida em que possuem uma atitude crítica em relação ao conhecimento sobre o trabalho, podem enfrentar esses silenciamentos e discriminações veladas, buscando formas de superar, ou mitigar, os efeitos do racismo institucional.

\section{Análise crítica do trabalho: perspectivas de descolonização}

A hierarquização do saber e a produção de um modelo ancorado nos padrões eurocêntricos assumem papel de destaque não só no que diz respeito à educação formal e à produção de conhecimento, mas também nas relações de trabalho constituídas na esteira da modernidade. Os estudos sobre o trabalho desenham um campo de produção de conhecimento que acompanha a modernidade e inscrevem-se nas problematizações do contemporâneo e da vida de nossos dias. Tamanha força e intensidade colocam esta temática no centro das questões da vida atual e cotidiana, criando fluxos que ora tomam o trabalho como raízes e núcleos de sustentação da situação socioeconômica, ora como linha transversal que se produz no emaranhado das relações sociais, configurando subjetividades, modos de viver e trajetórias de vida. 
A análise crítica do trabalho acompanha sua própria história no capitalismo, haja vista as perspectivas de Marx, Durkheim e Weber na crítica ao trabalho capitalista que seguem produzindo efeitos de desacomodação até nossos dias. Evidente que, como força e movimento, também o trabalhar se modifica e se atualiza, gerando outros elementos para a produção de uma atitude crítica. Assim, uma posição crítica com relação ao trabalho vai colocar em questão os jogos de poder e de verdade que o configuram na sociedade, pressionando para a cristalização de certas formas de dominação que impedem os movimentos e podem funcionar como estratégias de aprisionamento. Também indicam resistências e contrafluxos, que podem provocar movimentos de deslocamento e de produção de modos singulares de trabalhar e produzir.

A discussão sobre as estratégias de governo -com suporte foucaultiano- faz referência $s$ artes de governar que se produzem a partir do século XVI no ocidente, onde o "governar" utiliza-se dos modos de funcionamento do poder pastoral, mas deslocado de seu conteúdo religioso, e que se multiplica em domínios variados, como a casa, as crianças, o Estado. A atitude crítica, então, seria uma atividade de desacomodação com relação a estas formas de governo de si, do viver, da sociedade. $\mathrm{O}$ autor busca situar a noção de crítica na perspectiva histórico-filosófica, que aborda o conhecimento como estratégia de poder e de produção de verdades, cujo efeito disciplinador se torna visível nas práticas do conhecer e, neste caso, do trabalhar e do viver. A posição crítica, portanto, não é exclusiva da ordem de afrontar uma racionalidade, mas de desvendar as tramas de poder que permitem sua existência e fortalecimento. No mbito do trabalho, as estratégias de governo têm sido abordadas, por exemplo, como formas de regulação da relação Estado-Social e indivíduo no mbito do trabalho nas políticas públicas (Crespo, Revilla \& Serrano, 2009 ou na forma de um "governo por números" (Sisto, 2017, apontando a gestão pela relação financiamento-produtividade nas universidades chilenas.

Compondo núcleos significativos da vida social, o trabalho coloca-se nos jogos de força que compõem o viver, indicando as linhas duras que sujeitam o Trabalho ao Capital, nos modos de produção do capitalismo, e, ao mesmo tempo, como força produtora de novos modos de viver, de conhecer e, até mesmo, de trabalhar. Neste jogo, trabalhar pode ser entendido como movimento, em que as resistências e formas de dominação podem agenciar-se e conformar-se como espaços enrijecidos e/ou produzir-se como deslocamentos e contrafluxos. Trata-se, portanto, de conceber o trabalho como força e movimento, que se configura como dispositivo fundamental de produção da vida em sociedade e dos modos de viver. Assim, o trabalho produzse nas redes de poder e de verdade, que lhe conferem forma e estrutura, institucionalizando certas verdades sobre o trabalho e o trabalhar e pressionando para que se formate em certas condições e possibilidades.

Os estudos sobre trabalho e subjetividade tomam maior evidência na América Latina a partir da segunda metade do século XX, ainda que possamos encontrar estes temas em estudos anteriores. Estes estudos partiram, necessariamente, de uma crítica a uma concepção de trabalho centrada nos elementos socioeconômicos e, do mesmo modo, em uma concepção de classe que priorizava, também, a situação socioeconômica aos elementos culturais e aos modos de viver. Esta perspectiva, por um lado, situava-se no campo do marxismo, retomando as críticas da chamada "nova escola inglesa", colocando em cena as noções de experiência e suas articulações com a psicanálise e a antropologia (Thompson, 1981. Por outro lado, colocavase em consonncia com a perspectiva pós-estrutural francesa, através, principalmente, da problematização das noções de poder, de dominação e de resistência.

Do ponto de vista da concepção de subjetividade a crítica dirigia-se para a noção individualista e intimista, centrada na ideia de sujeito autônomo e livre. Esta posição crítica vai criando condições de possibilidade para a redefinição da perspectiva dos estudos nesta área, tomando o sujeito trabalhador, sua experiência, trajetórias de vida, e os modos como o trabalho pode constituir-se como dispositivo de produção de modos de viver. Os temas da identidade e dos cotidianos de trabalho, analisados desde os pressupostos da etnografia, também aparecem como constitutivos destes estudos (Coutinho, Oliveira, \& Sato, 2016. Estas abordagens da temática do trabalho ampliam suas análises do mbito organizacional e inscrevem a problematização do trabalho em outros espaços da vida social, constituindo um campo de análise que implica, por exemplo, 
nos estudos sobre desemprego, saúde do trabalhador ou estratégias de consumo e de ética solidária. Deste modo, coloca-se uma problematização do trabalho e da subjetividade no campo da psicologia social crítica, enfatizando o caráter ético-político dos estudos sobre o trabalho e os movimentos de resistência que se produzem no âmbito das relações de poder e de dominação.

Esta análise crítica do trabalho coloca em cena, também, uma crítica ao próprio conhecimento produzido no âmbito acadêmico e científico, que dá evidência à racionalidade dos modelos de gestão e de organização dos processos de trabalho, pautada na perspectiva taylorista-fordista e na distinção entre trabalho manual e intelectual, dotando de supremacia o segundo e subjugando os saberes práticos e da experiência às lógicas racionais desta administração científica. Pode-se dizer que, de certa forma, estes processos de colonização das experiências dos trabalhadores pelos modos "racionais" de administração científica impõem-se com o capitalismo até os nossos dias. Pulido (2007) aponta que a psicologia ligada ao trabalho raramente se ocupa em pensar as condições particulares onde se realiza, mas de discutir os aspectos metodológicos na implementação de modelos de gestão e de trabalho produzidos, sobretudo, em países nor-atlanticos e, em seus estudos, norte americanos. O autor utiliza a expressão "modernizando a mente" (Pulido, 2004) para pensar as estratégias psicológicas para forjar a ideia de "homem moderno" nos trabalhadores dos países não industrializados. A busca de implementação destes "modelos" leva a uma relação de proximidade ou não de uma experiência ideal, mais do que uma análise das condiçóes e situações onde esta experiência se produz.

Vale lembrar que as estratégias de gestão das subjetividades para o trabalho vêm assumindo cada vez mais importância em contextos de trabalho imaterial (Lazzarato \& Negri 2001), como no contemporâneo. A motivação para o trabalho, tema recorrente nos estudos sobre estratégias de gestão tradicionais, vem sendo associado à psicologia positiva e seus desdobramentos na especificidade do trabalho, indicando que as subjetividades adquirem cada vez mais importância como objeto das estratégias de gestão.

Tais estratégias aparecem como elemento importante na análise da colonização do trabalho e, sobretudo, da colonização da subjetividade no trabalho. Reafirmando, muitas vezes, a separação entre o trabalho manual e o intelectual, assim como apostando em estratégias de gestão de espírito colonizador, que não levam em consideração os saberes locais, produzidos nas práticas cotidianas. Lazzarato e Negri (2001, p.12), ao afirmarem que a subjetividade "desce ao chão da fábrica", não indicam um reconhecimento aos investimentos subjetivos de trabalhadoras e trabalhadores, mas, sim, que a própria subjetividade se torna objeto deste processo.

A perspectiva crítica do trabalho, tal qual a crítica descolonial, produz-se no bojo dos movimentos de resistência dos anos setenta, sendo o movimento feminista uma importante referência. Ou seja, a discussão sobre gênero e trabalho trouxe para o centro da segunda, a discussão sobre trabalho doméstico e a configuração das relações de poder que subjugam as mulheres neste contexto. Deste modo, estas abordagens ampliam as análises da divisão sexual do trabalho para levar em conta os elementos históricos e culturais ligados ao patriarcalismo. A publicação de "A classe operária tem dois sexos" (Lobo, 1991) foi um marco nesta discussão no Brasil, assim como os estudos multicêntricos de Kergoat e Hirata (2008), dando visibilidade aos modos como gênero e trabalho se produziam como dispositivos de dominação e disciplinamento nas articulações entre capitalismo e patriarcado.

Do ponto de vista da articulação entre subjetividade, trabalho e raça, destacam-se neste mesmo período os estudos de Bento (1995) e de Agier, Castro e Guimarães (1998) que, a partir de uma perspectiva antropológica, traziam para a análise do trabalho os marcadores raciais e seus efeitos, principalmente no acesso ao trabalho e à mobilidade social, em estudos realizados na Bahia - Brasil.

A partir destes estudos no campo, sobretudo, das ciências sociais, as temáticas de gênero e raça adquirem maior visibilidade e passam a compor não só campos de estudos, mas formas de analisar, indicando sua identidade com a perspectiva de uma epistemologia feminista. Davis (2016) identificou as articulações entre mulheres, raça e classe, mostrando a singularidade da experiência histórica das mulheres negras. Enquanto o feminismo branco apontava para o ingresso da mulher no mercado de trabalho, o feminismo negro mostrava 
uma mulher, desde a escravidão, trabalhando no campo, no trabalho doméstico e em posições extremamente precárias no mercado de trabalho, operando efeitos até os dias atuais.

Martins (2011, p. 8 pensa o Brasil como uma sociedade de história lenta, com relações socialmente arcaicas, que mediatizam, viabilizam ou impedem o desenvolvimento social e político. Nesta perspectiva, aponta que a escravidão indígena e negra, marcos da história do trabalho do Brasil colonizado, seguem operando efeitos até hoje, sobretudo, na forma do endividamento manipulado. A tensão entre a lógica escravagista e a da formação de trabalhadoras e trabalhadores livres, aos moldes de pensamento liberal, segue até nossos dias, operando violências de ordem subjetiva nos contextos de trabalho. Estas violências podem operar através de formas de desqualificação de trabalhadoras e trabalhadores, sempre devedores de escolarização, de formação, de capacitação, para ascenderem a patamares mais elevados na hierarquia de trabalho. O modelo de homem branco ocidental segue operando como referente para a definição de um "bom" trabalhador, sustentando relações hierárquicas no trabalho e subjugando os saberes práticos e localizados, forjados nas experiências de trabalho.

Por este motivo, abordar o trabalho desde uma perspectiva descolonial necessita trazer tona os silenciamentos e invisibilidades que esta concepção de "bom" trabalhador acabou por produzir como, neste caso, as questões ligadas ao gênero e raça.

\section{"O trabalho como arte: reinventando modos de trabalhar e de viver"}

Neste texto, abordaremos as relações entre trabalho, gênero e raça através do recorte de um estudo mais amplo chamado "O trabalho como arte: reinventando modos de trabalhar e de viver", que está em desenvolvimento junto a trabalhadoras e trabalhadores das políticas públicas em saúde e assistência, na cidade de Porto AlegreBrasil. Acreditamos que as problematizações ensejadas por tal estudo podem permitir o desenho de algumas análises, de maneira localizada, sobre os processos de colonização do saber e do trabalho que subjugam o Sul global.

Neste estudo, discutimos os modos de trabalhar, focando, principalmente, as experiências cotidianas que agenciam os saberes práticos. Deste modo, o eixo central são os processos de produção dos saberes forjados nas experiências, ressaltando os modos como as prescrições e normativas próprias s atividades se singularizam nas experiências, o que, nas clínicas do trabalho, poderia ser pensado como trabalho real (Schwartz, 2011. Do ponto de vista dos estudos sobre as configurações do trabalho, tal questão estaria associada s práticas anônimas (De Cerateau, 1998 ou aos saberes práticos (Martins, 2014. Estes processos de torção das prescritivas e normativas para que se tornem efetivas na realização do trabalho podem ser entendidas como gestão, no seu sentido mais amplo, onde a gestão transversaliza todo o processo, em diferentes planos, desde o planejamento até a execução efetiva das tarefas. Este estudo, portanto, priorizou o acompanhamento dos cotidianos de trabalho, tendo como principal ferramenta os diários de campo, relatos de observação do trabalho e a realização de oficinas de fotografia. Esta metodologia tem como objetivo discutir os modos de trabalhar, identificando as linhas de visibilidade que podem indicar os aspectos mais visíveis e, portanto, mais institucionalizados dos modos de trabalhar, na relação que estabelecem com aqueles menos visíveis e, de certa forma, menos reconhecidos pelos próprios trabalhadores e trabalhadoras.

Assim, o recurso fotográfico não foi utilizado como "prova" de uma possível "realidade" de trabalho, mas como produção de imagens, em que o conteúdo visual das fotografias mostrava as tensões entre os elementos mais ou menos visíveis destes cotidianos. Tomando como referência a leitura deleuziana da perspectiva de Foucault sobre os jogos de visibilidade, é importante destacar a distinção entre as linhas de visibilidade e os elementos visuais que sustentaram a análise das fotografias. A "visibilidade produz-se nas condições históricas, políticas, culturais, institucionais, sociais, nas quais os sujeitos também são uma produção e um lugar neste visível" (Tittoni \& Prudente, 2014, p. 26). Buscar as linhas de visibilidade é, assim, utilizar-se dos 
recursos visuais para pensar os elementos mais evidentes do trabalho e aqueles cuja expressão, até mesmo pela proximidade e familiaridade, não alcançam a mesma intensidade.

Buscar as linhas de visibilidade é problematizar os jogos de visibilidade que se produzem nos cotidianos de trabalho, como efeitos das relações de poder e de verdade. Considerando que a história moderna do trabalho dá maior visibilidade aos aspectos técnicos, normativos e prescritivos, os saberes práticos e cotidianos geralmente possuem menor visibilidade. Desde uma perspectiva descolonial, no seu aspecto micropolítico, pensar os modos como trabalhadoras e trabalhadores enfrentam as prescrições do trabalho e as recriam a partir de sua experiência mostra-se como um caminho interessante para instigar um pensamento crítico, ético e reflexivo.

As fotografias destacadas destas experiências fotográficas mostram duas profissionais da saúde, uma enfermeira e uma agente comunitária de saúde que fazem parte de uma equipe de saúde da Atenção Básica da cidade de Porto Alegre. Estas imagens foram produzidas pela pesquisadora, sob orientação das profissionais, através da consigna que solicitava que a produção das imagens pudesse mostrar o trabalho realizado.

A equipe de saúde da família é o ponto de sustentação da atenção básica no Sistema Único de Saúde brasileiro, sendo a porta de entrada para todo o sistema e organizada de forma territorializada. A equipe básica está formada por medicina de família, enfermagem (nível técnico e superior) e agentes comunitárias de saúde, que são trabalhadoras moradoras do território, que fazem a busca ativa de usuários, visitas domiciliares, acompanhamento de usuários com dificuldade de locomoção e uma série de outras atividades que permeiam as relações entre os usuários e usuárias, equipamentos de políticas públicas e a equipe de saúde da família. As equipes de saúde da família, além de fazer o atendimento clínico da população do território adstrito, desenvolver os programas específicos da atenção básica, como acompanhamento de gestantes, bebês, hipertensos, diabéticos, aplicação e controle de vacinas, também produzem atividades de promoção de saúde, como os Programas de Saúde na Escola. As agentes comunitárias de saúde são um elemento que faz diferir a atenção básica, pois trazem para a equipe de saúde seus conhecimentos práticos e cotidianos, forjados neste espaço ambíguo e híbrido entre os saberes técnicos e clínicos e seus desdobramentos nas práticas cotidianas. Vieira e Tittoni (2015) traduziram seu trabalho na figura do artífice, apoiados na discussão proposta por Sennet (2009), considerando que o artífice produz algo novo ao recriar cotidianamente as relações entre o conhecimento técnico, formal e os saberes práticos.

As fotografias foram produzidas pela equipe de pesquisa, sob orientação das trabalhadoras, a partir do acompanhamento semanal desta equipe de saúde por dez meses, em atividades de ensino e formação de ensino em serviço. Neste acompanhamento foram sendo produzidos diários de campo para registros das observações e das narrativas cotidianas. Das fotografias produzidas, destacamos duas para orientar as reflexões propostas neste texto, que mostram duas profissionais da saúde, uma enfermeira e uma agente comunitária de saúde que fazem parte de uma mesma equipe de saúde da família. Todas as fotografias foram produzidas e levadas para discussão do grupo, que levantou vários pontos de reflexão sobre seu trabalho. Destacam-se os vários recursos utilizados para explicar aos usuários e usuárias, em alguns casos, analfabetos, como proceder a administração de medicamentos. As equipes de saúde e, principalmente as agentes comunitárias de saúde, criaram uma simbologia para indicar o horário dos medicamentos e as formas de uso muito interessante, mas que abrem uma discussão que extrapola, em muito, o âmbito deste artigo. Estas duas imagens foram escolhidas pois o marcador raça foi identificado nelas. Ou seja, as mãos qualificadas como negras, independentemente da pessoa que aparece na fotografia, forram assinaladas na imagem da agente comunitária de saúde, tendo sido associada às luvas brancas da outra fotografia. As análises foram produzidas pela equipe de pesquisa, a partir dessas aberturas.

Sobre o tema aqui proposto, pode-se pensar em dois aspectos: um primeiro, que indica o atravessamento de gênero nas profissões de cuidado, bastante explorada pela literatura. E, um segundo, que identifica as diferenças de classe mostradas através do marcador de raça, produzindo uma ligação entre a profissão de nível superior branca e a agente comunitária, negra. 


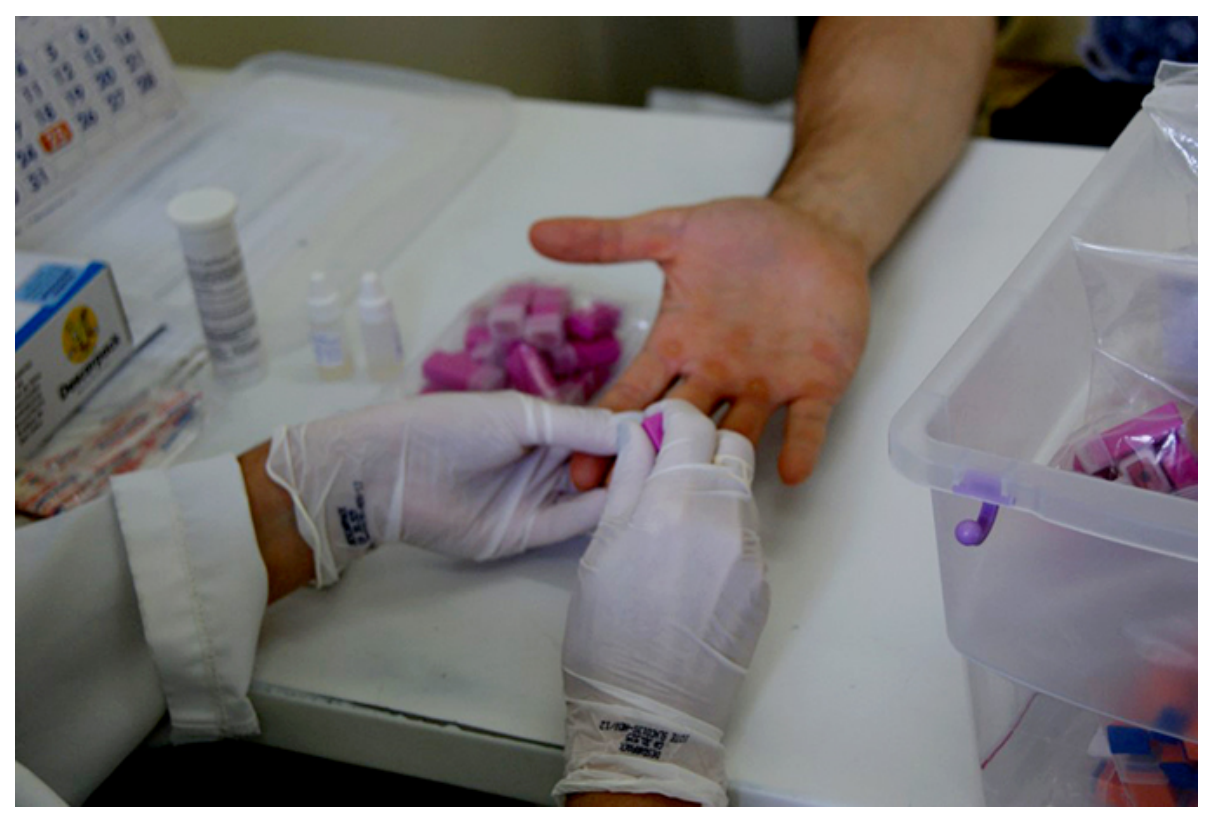

FIGURA 1

Fonte: os autores.

Em um primeiro momento, destaca-se a visibilidade das mãos, ainda que o trabalho em saúde seja, em muitos aspectos, marcado pela imaterialidade, sobretudo enquanto atividade de acompanhamento e promoção de saúde, como ocorre na Saúde da Família. As mãos, no entanto, mostram atividades distintas: na fotografia 1 (figura 1), as mãos brancas de uma enfermeira, e, na fotografia 2 (figura 2), as mãos negras de uma agente comunitária de saúde. A agente comunitária de saúde é uma trabalhadora que se diferencia na equipe da Atenção Básica, pois é necessariamente uma moradora do território, que faz o acompanhamento de usuárias e usuários fora da unidade de saúde, tendo a visita domiciliar como o recurso mais importante de seu trabalho. Está ocupada em acompanhar e registrar a situação dos moradores e moradoras do território adstrito à unidade onde trabalha e acompanhar as ações de saúde de cunho individual e coletivas.

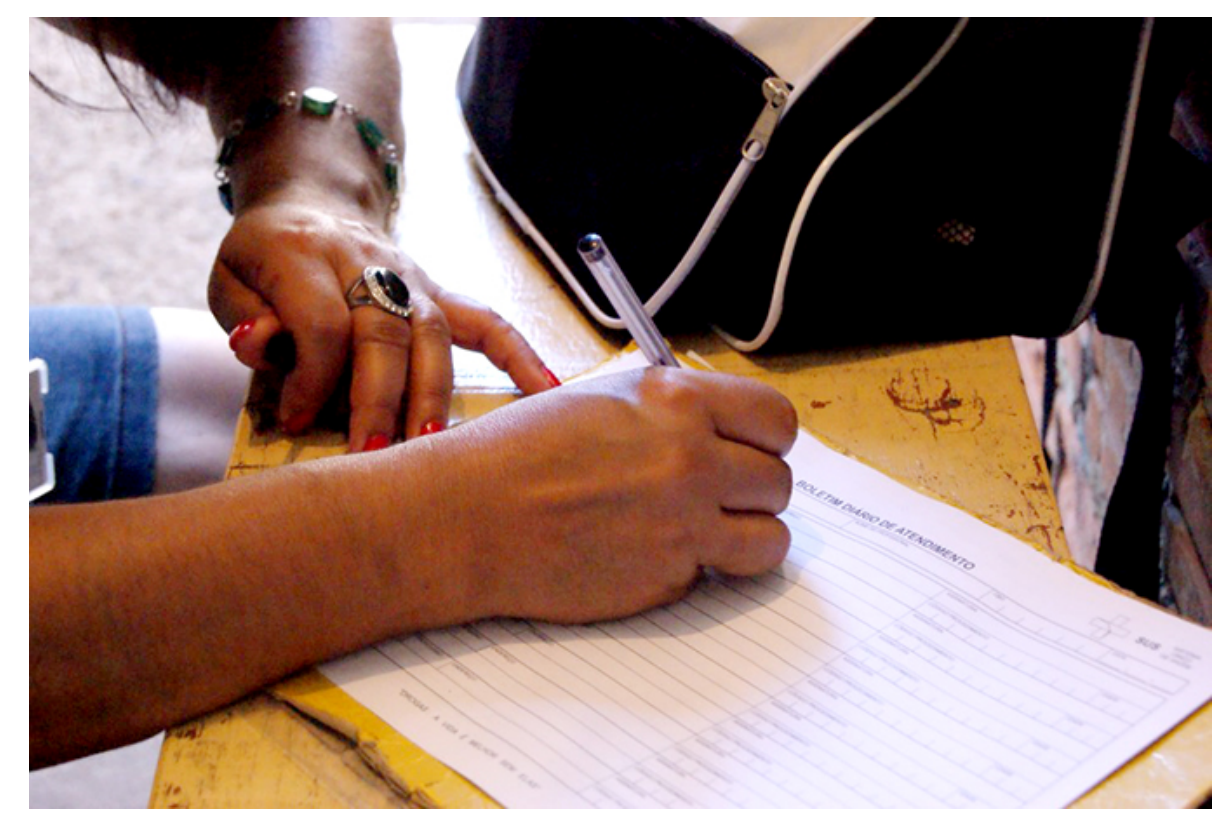

FIGURA 2

Fonte: os autores. 
Nessas fotografias, o elemento visual -as mãos- indica importantes linhas de visibilidade do trabalho destas trabalhadoras. No caso da agente comunitária de saúde, as mãos manipulam instrumentos de registro e mostram uma atividade que, comumente, não é ligada ao modelo tecno-centrado de concepção da saúde. Já na fotografia 2 (figura 2), as mãos manipulam instrumentos técnicos -agulhas, medicamentos- que são materiais comumente associados ao trabalho em saúde, no modelo tecno-centrado mais evidente. São mãos recobertas por luvas que, diferentemente da primeira imagem, não tocam o usuário diretamente, pois estão higienizadas e esterilizadas para um procedimento técnico. Em um caso, as mãos estão em uma experiência de proximidade e, no outro, de distanciamento e de separação.

Nestas imagens, as linhas de visibilidade identificam que o trabalho menos marcado pelo caráter técnico (comumente associado às populações menos favorecidas economicamente), também é aquele com maior proximidade com os territórios, com os usuários e com as contingências que os modos de viver imprimem às formas de produção de saúde. As imagens mostram que as atividades e os equipamentos envolvidos no trabalho destas profissionais da saúde diferem muito, sendo que a atividade da fotografia 1 (figura 1) está mais próxima do que a produção de conhecimento reconhece como trabalho em saúde, pautado em um entendimento de saúde tecnocentrado. Na fotografia 2 (figura 2), de imediato, não se identifica a atividade como sendo do campo da saúde, sendo necessário um olhar mais apurado sobre os formulários que estão sendo preenchidos. Assim, a concepção de saúde médico-centrada e tecno-centrada, sustentada pela discursividade acadêmica e científica, pode invisibilizar atividades importantes e necessárias ao trabalho na atenção básica, como a das agentes comunitárias de saúde, por não estarem codificadas neste discurso hegemônico. Pode ocorrer alguma forma de desqualificação dos saberes produzidos por estas trabalhadoras, justamente porque sua imersão neste espaço híbrido, onde os saberes técnicos e práticos estão tensionados, pressiona para problematizar as concepçóes de saúde hegemônicas. Associar o marcador raça a este lugar menos valorizado (menor salário, menor escolarização, por exemplo) na hierarquia do trabalho, apesar do reconhecimento de sua importância, mostra que a imagem da trabalhadora negra realizando o seu trabalho torna visível as invisibilidades aí presentes, como o acesso desigual à escolarização, formação e qualificação para o trabalho.

Assim como as imagens produzidas a partir das oficinas de fotografia mostram as relações entre trabalho e raça no Brasil, podemos lançar mão de outros dados que também indicam estes tensionamentos. De certo modo, como uma fotografia, os dados estatísticos sobre o trabalho no Brasil vêm corroborar as linhas de visibilidade que as imagens produzidas deixam mais evidentes.

No Brasil, a Pesquisa Nacional por Amostra de Domicílios (IBGE, 2018), realizada nos meses iniciais do primeiro semestre de 2018, mostra que a grande maioria da população menos escolarizada deverá ocupar postos de trabalho de menor remuneração. Isto porque, na maioria das situações, não teve acesso ao ensino superior, confirmando o lugar marginalizado que a separação disciplinar operada pela colonialidade vem produzindo. Esta mesma base de dados indica que as mulheres são a maioria entre as pessoas em idade de trabalhar, representando $52,4 \%$ da população. No entanto, entre as pessoas ocupadas, existe predominância de homens, $63,6 \%$, contra 44,5\%; e as mulheres, quando inseridas no mercado de trabalho, ainda têm menor remuneração que os homens, mesmo apresentando escolaridade superior.

Do ponto de vista do marcador de raça e considerando as pessoas ocupadas no Brasil, 55,7\% são negros (pardos e pretos). No primeiro semestre de 2018, houve um crescimento do nível de ocupação entre pessoas brancas e pardas, sendo que as pessoas brancas ocupam 55,9\% dos postos de trabalho. No entanto, entre as pessoas desocupadas, a pesquisa mostra que a relação racial está invertida, pois no primeiro semestre de 2018 aumenta o percentual de pardos e pretos desocupados e reduz-se o de brancos - pardos 52,6\%, pretos $11,6 \%$ e brancos $35,2 \%$. Assim, o percentual de pessoas negras desocupadas aumentou, enquanto reduz-se o percentual de pessoas brancas nesta condição.

Estes dados indicam, também, linhas de visibilidade de como os marcadores gênero e raça estão colocados nos contextos de trabalho. Pode-se perceber sua variação nos últimos anos, mostrando que o sujeito homem branco ainda é o modelo mais evidente do que se pode considerar como a população inserida no mercado de 
trabalho. Em momentos de crise social, política e econômica, como estamos vivendo, esta tendência tende a se afirmar.

A perspectiva de colonização das subjetividades no trabalho faz pensar que este modelo de trabalhador -homem e branco- acaba por impor-se estatisticamente e como modelo de sujeito que pressiona para as experiências de si e para as formas de reconhecimento do sujeito. Os marcadores de raça e de gênero indicam que o acesso à educação ainda não produz efeitos de mobilidade de ascendência para as mulheres, pois ainda que mais escolarizadas, estão menos presentes no mercado de trabalho. Da mesma forma, as políticas afirmativas para a diversidade racial no mercado de trabalho ainda produzem efeitos frágeis que, em momentos de crise, sofrem sérios reveses. A população mais atingida pela desocupação é a população negra, inclusive em mobilidade descendente, confirmando a tendência de embranquecimento da mão-de-obra que se apresentou no Brasil pós-abolição da escravatura: abandona-se o uso da mão-de-obra de pessoas negras, relegando-as a funções mais marginalizadas -e isso quando ainda as tem- e valorizando a mão-de-obra dos homens brancos para a maioria das funções no mercado de trabalho.

Aqui, tanto as fotografias quanto os dados estatísticos, cada qual a sua maneira, constituem imagens acerca das relações de trabalho, gênero e raça no Brasil. Desse modo, as estratégias metodológicas ligadas à produção de imagens e, aqui, de fotografias, podem compor com dados estatísticos, a partir da ideia de foto-estatística, em que linhas de visibilidade se entrelaçam, fazendo ver aquilo que se apresenta para além da série de pixels organizada.

As reflexões produzidas sobre as inter-relações entre trabalho, conhecimento e subjetividade a partir de uma crítica descolonial, afirmam a importância de tornar visível as diversidades que compõem as análises de trabalho, dando evidência para as variabilidades e as formas singulares que adquirem nas experiências localizadas. Ao retomarmos as questões originárias deste estudo, isto é "o que pode uma perspectiva crítica do trabalho", pode-se pensar que produzir estas linhas de visibilidade sobre os marcadores de raça e gênero no trabalho pode tornar mais evidente o modelo ocidental e europeu do trabalhador homem e branco, que segue produzindo efeitos de colonização. No trabalho contemporâneo, fortemente sustentado pela perspectiva individualista, meritocrática e competitiva, afirmada no pensamento neoliberal atual, este modelo opera como o padrão a ser seguido, apesar da variabilidade e diversidade de trabalhadoras e trabalhadores.

\section{Considerações finais}

A partir das análises realizadas, pode-se perceber que tanto a produção de conhecimento, quanto as relações de trabalho que se apresentam na esteira da modernidade e atravessam o Sul global estão sob jugo colonial, nas tensões de poder, produzindo dominação e resistências. Dessa forma, saber e trabalho entram em uma lógica de inter-relação em que a colonialidade de um alimenta a de outro, reproduzindo e reafirmando uma série de processos de dominação balizados por uma epistemologia hegemônica. Assim, o saber pressionado pela episteme do Norte global, subjetiva, também, a lógica do trabalho, podendo contribuir para a manutenção e enrijecimento dos processos de trabalho e dos lugares atribuídos a partir dos marcadores de classe, raça e gênero.

Encarar tais problemáticas a partir de uma perspectiva descolonial exige aquilo que Mignolo (2008) vai chamar de desobediência epistêmica. Ao lançar mão de tal conceito, o autor aponta-o como uma das pedras fundamentais do pensamento descolonial; seria a capacidade de ultrapassar os limites das teorias eurocêntricas que desempenham um papel universalista na dita episteme moderna. $\mathrm{O}$ autor segue:

Sem tomar essa medida e iniciar esse movimento, não será possível o desencadeamento epistêmico e, portanto, permaneceremos no domínio da oposição interna aos conceitos modernos e eurocentrados, enraizados nas categorias de conceitos gregos e latinos e nas experiências e subjetividades formadas dessas bases, tanto teológicas quanto seculares. (Mignolo, 2008, p. 288) 
A proposta dessa desobediência epistêmica não caminha em um sentido de deslegitimação da produção de conhecimento do "primeiro mundo" e sim do questionamento de seu lugar sagrado e balizador de saberes e costumes. As produções intelectuais eurocêntricas não são consideradas, nesse texto, hierarquicamente superiores, nem um saber ao qual os países colonizados devem ser sujeitados. A apropriação de saberes pode ser pensada como uma produção subjetiva e antropofágica onde

engolir o outro, sobretudo o outro admirado, de forma que partículas do universo desse outro se misturem às que já povoam a subjetividade do antropófago e, na invisível química dessa mistura, se produza uma verdadeira transmutação. Constituídos por esse princípio, os brasileiros seriam, em última instância, aquilo que os separa incessantemente de si mesmos. Em suma, a antropofagia é todo o contrário de uma imagem identitária. (Rolnik, 2010, p. 452)

Agamben (2007) atribui à produção de conhecimento dessa modernidade eurocentrada o caráter de religião, o que significa dizer que ela sacraliza conhecimentos a partir de estratégias de poder que hierarquizam saberes e excluem aquilo que não é considerado digno e merecedor de um assento no panteão epistemológico da modernidade. O mesmo autor nos apresenta a ideia de profanação para tensionar esse lugar sacralizado. Segundo ele, profanar significa devolver ao uso comum, restituir ao livre uso aquilo que é tido como sagrado. Ao conceituar profanação, o autor não pretende que a restituição ao livre uso daquilo que outrora foi sagrado produza uma homogeneidade que anulará qualquer diferença. Segundo ele, profanar "não significa simplesmente abolir e cancelar as separações, mas aprender a fazer delas um uso novo, a brincar com elas" (Agamben, 2007, p. 67).

A realização deste estudo possibilitou, assim, que emergissem dos cotidianos de trabalho, as relações entre gênero, raça e classe social, fazendo pensar sobre os modos como estão articulados. A partir desta evidência, identificada pela problematização das linhas de visibilidade e corroborada pelos dados estatísticos, pode-se pensar os efeitos de colonização que o conhecimento produzido sobre o trabalho produz. Estas questões abriram outras janelas e trouxeram outros autores, não como companheiros de uma articulação teórico conceitual de suporte deste texto, mas como parceiros de novos caminhos nos percursos da descolonialidade e do trabalho.

\section{Referências}

Agamben, G. (2007). Profanações, 1 ed. São Paulo, SP: Boitempo.

Agier, M., Castro, N.A. \& Guimarães, A. (1998). Imagens e Identidades do Trabalho. São Paulo: Hucitec.

Bento, M. A. (1995). A mulher negra no mercado de trabalho. Revista Estudos Feministas, 02, 479-488. Retrieved 27 March, 2019, from https://periodicos.ufsc.br/index.php/ref/article/view/16466/15036

Carmichael, S., \& Hamilton, C. (1967). Black power: The politics of liberation in America. New York: Vintage.

Castro-Gómez, S. \& Grosfogujel, R. (eds.), (2006). El giro decolonial. Reflexiones para una diversidad epistémica más allá del capitalismo global. Bogotá: Iesco, Pensar, Siglo del hombre Editores.

Castro-Gómez, S. (2007). Decolonizar la Universidad. La hybris del punto cero y el diálogo de Saberes. In J. L. Saavedra (ed.), Educación superior, interculturalidad y descolonización (pp. 291-307). La Paz: Programa de Investigación Estratégica en Bolivia y Comité Ejecutivo de la Universidad Boliviana.

Cohen, E. A. (2004). A história e a hiperpotência. Política Externa, 13(3).

Costa, C. (2014). Feminismos descoloniais para além do humano. Estudos Feministas, 929-934. Retrieved 27 March, 2019, from https://periodicos.ufsc.br/index.php/ref/article/viewFile/36754/28576

Coutinho, M. C., Oliveira, F. \& Sato, L. (2016). Olhar o cotidiano: percursos para uma psicologia social do trabalho. Psicologia USP, 27(2), 289-295. http://dx.doi.org/10.1590/0103-656420140053.

Crespo, E., Revilla, J. \& Serrano, A. (2009). Del gobierno del trabajo al gobierno de las voluntades: caso de la activación. Psicoperspectivas, VIII(2), 82-101. Retrieved 27 March, from http://www.psicoperspectivas.cl

Davis, A. (2016). Mulheres, Raça e Classe. São Paulo: Boitempo. 
De Cerateau, M. (1998). A invenção do cotidiano. Petrópolis: Vozes.

Dreyfus, H., \& Rabinow, P. (1995). Michel Foucault Uma trajetória filosófica: para além do estruturalismo e da hermenêutica. Rio de Janeiro: Forense Universitária.

Foucault, M. (1988). El sujeto y el poder. Revista Mexicana de Sociología, 50(3), 3-20.

Foucault, M. (1990). O que é a crítica? (Crítica e Aufklärung). Bulletin de la Sociétéfrançaise de philosophie, 82(2), 5-63. Retrieved 27 March, 2019, from http://michel-foucault.weebly.com/uploads/1/3/2/1/13213792/critica.pdf

Foucault, M. (1995). O sujeito e o poder. In P. Rabinow \& H. Dreyfus (eds.), Michel Foucault: uma trajetória filosófica (para além do estruturalismo e da hermenêutica) (pp. 231-249). Rio de Janeiro: Forense Universitária.

Foucault, M. (1999). A ética do cuidado de si como prática da liberdade. In M. Foucault (ed.), Ética, Estética e Hermenêutica (pp. 393-417). Barcelona: Paidós.

Foucault, M. (2000). As Palavras e as coisas. São Paulo, SP: Martins Fontes.

Foucault, M. (2004). Ética, Sexualidade e Politica. Rio de Janeiro, RJ: Forense Universitária.

Foucault, M. (2005). Em defesa da sociedade: curso no Collège de France, 1975-1976. São Paulo: Martins Fontes.

Gomes, N. L. (2012). Relações étnico-raciais, educação e descolonização dos currículos. Currículo sem Fronteiras, 12(1), 98-109.

Instituto Brasileiro de Geografia e Estatística. (2018). Pesquisa Nacional por Amostra de Domicílios Contínua. Rio de Janeiro: IBGE.

Kergoat, D., \& Hirata, H. (2008). Divisão Sexual do Trabalho profissional e doméstico: Brasil, França e Japão. In Costa et al. (eds.), Mercado de Trabalho e Gênero: comparações internacionais (pp. 263-278). Rio de Janeiro: Editora FGV.

Lazzarato, M., \& Negri, A. (2001). Trabalho Imaterial, 2 ed. Rio de Janeiro: DP\&A.

Lobo, E. S. (1991). A classe operária tem dois sexos. São Paulo: Editora Brasiliense. Retrieved 27, March, 2019, from h ttps://portalseer.ufba.br/index.php/crh/article/view/18820/12190

Pulido M., H. C. (2007). Produciendo trabajadores modernos: conocimiento psicológico y el mundo del trabajo en el sur. Universitas. Psychology, 6(1), 27-37.

Martins, J. S. (2014). Uma sociologia da vida cotidiana: ensaios na perspectiva de Florestan Fernandes, de Wright Mills e de Henri Lefebvre. São Paulo: Editora Contexto.

Martins, J. S. (2011). A política do Brasil - lúmpen e mistico, 1 ed. São Paulo: Contexto.

Mignolo, W. (2008). Desobediência epistêmica: a opção descolonial e o significado de identidade em política. Cadernos de Letras da UFF: Dossiê: Literatura, lingua e identidade, 34(1), 287-324. http://www.uff.br/cadernosdeletras uff/34/traducao.pdf

Mignolo, W. (2009). Desobediencia epistémica (II), pensamiento independiente y libertad decolonial. Otros logos, Revista de Estudios Críticos, 1(1), 8-42. http://www.ceapedi.com.ar/otroslogos/revistas/0001/mignolo.pdf

Orellana, R. C. (2008). Foucault e o cuidado da liberdade - ética para um rosto de areia. Santiago: LOM Ediciones.

Restrepo, E., \& Rojas, A. (2010). Inflexión decolonial: fuentes, conceptos y cuestionamientos. Popayán: Instituto Pensar: Editorial Universidad del Cauca.

Rolnik, S. (2010). Esquizoanálise e antropofagia. In E. Allienz (ed.), Gilles Deleuze, uma vida filosófica (pp. 451-463). São Paulo: Editora 34.

Schwartz, Y. (2011). Conceituando o trabalho, o visível e o invisível. Trabalho, Educação e Saúde: Rio de Janeiro, 9(1), 19-45. http://dx.doi.org/10.1590/S1981-77462011000400002

Sennet, R. (2009). O artifice, 2. Ed. São Paulo: Record.

Sisto, V. (2017). Gobernados por números: El financiamiento como forma de gobierno de la universidad en Chile. Psicoperspectivas, 16(3), 64-75. https://doi.org/10.5027/psicoperspectivas-vol16-issue3-fulltext-1086

Spivak, G. C. (2010). Pode o subalterno falar? Belo Horizonte: Ed.UFMG.

Thompson, E. P. (1981). A miséria da teoria ou um planetário de erros. Rio de Janeiro: Zahar Editores. 
Tittoni, J., \& Prudente, J. (2014). A pesquisa intervenção como exercício ético e a metodologia como paraskeué. Fractal, Rev Psicol, 26(1), 17-28. http://dx.doi.org/10.1590/S1984-02922014000100003

Tittoni, J. (2009). Psicologia e Fotografia: experiências em intervençôes fotográficas. Porto Alegre: Dom Quixote.

Vieira, L. C., \&Tittoni, J. (2015). Entre imagens e palavras: as Agentes Comunitárias de Saúde como artífices. Pesquisas e Práticas Psicossociais, 10(1), São João del-Rei, 115-128.

Zambenedetti, G., \& Silva, R. A. (2011). Cartografia e genealogia: aproximações possíveis para a pesquisa em psicologia social. Psicologia \& Sociedade, 23(3), 454-463. Disponível online http://hdl.handle.net/10183/100237

\section{Notas}

* $\quad$ Artigo de pesquisa científica.

\section{Licencia Creative Commons CC BY 4.0}

Como citar: Tittoni, J., Castro, D., \& Gomes, A. (2019). Trabalho, raça e gênero na produção de fotografias: considerações a partir de uma experiência brasileira. Cuadernos de Administración, 32(58). https://doi.org/ 10.11144/Javeriana.cao32-58.trgpf 